\title{
DEVELOPMENT OF A MICROFABRICATED VAPOR PRECONCENTRATOR FOR PORTABLE ION MOBILITY SPECTROSCOPY
}

\author{
Michael Martin, Mark Crain, Kevin Walsh \\ Department of Electrical and Computer Engineering \\ University of Louisville \\ Louisville, Kentucky 40292
}

\author{
R. Andrew McGill, E.J. Houser, D. Mott, \\ Jennifer Stepnowski, Stanley V. Stepnowski, V. \\ Nguyen, Huey-Daw Wu \\ Naval Research Laboratory \\ Code 6375, Washington, DC 20375
}

\begin{abstract}
This work is part of the Cascade Avalanche Sorbant Plate ARray (CASPAR) project whose goals are the development of flow through preconcentrators that may be stacked into multiple planes for enhanced performance. These devices act as the front end of a portable Ion Mobility Spectrometer (IMS) for the detection of trace explosive or chemical agent vapors. We report on the design, simulation, fabrication and performance of $7 \mathrm{~mm} \times 7 \mathrm{~mm}$ polyimide preconcentrators. The devices are composed of dual serpentine platinum heaters supported by a 3-6 $\mu \mathrm{m}$ thick layer of polyimide suspended over a silicon frame. Early prototypes have demonstrated an order of magnitude improvement in detection threshold for a single plane when tested with a commercial portable explosive detector.
\end{abstract}

\section{INTRODUCTION}

The chemical preconcentrator described in this paper is a microfabricated hotplate that is coated with a polymer that selectively absorbs the analyte of interest at or near room temperature during the collection phase[1]. In this project the preconcentrator area was maximized to take advantage of the inlet diameter of a commercial hand held IMS explosive detection system[2]. This necessitated designing preconcentrators with active areas of up to $7 \mathrm{~mm} \times 7 \mathrm{~mm}$ which is a significant departure from other approaches[3]. In order to minimize both power consumption and thermal time constant, the heater traces are supported by a thin membrane. Several different approaches to heater support were investigated; a $2 \mu \mathrm{m}$ thick silicon nitride membrane, a $2 \mu \mathrm{m}$ thick heavily doped $\mathrm{p}++$ silicon layer, and a 6 um thick polyimide layer. Designs were initially evaluated at the University of Louisville by using the CoventorWare $^{\mathrm{TM}}$ Finite Element Analysis (FEA) software package to simulate operational characteristics. Then fabrication approaches were evaluated for the three designs. We report on the polyimide variety in this paper.

\section{DESIGN}

A number of design constraints are imposed on the preconcentrator by this application; the foremost being typical considerations for portable sensing. Namely, the component must minimize power consumption, have a small physical footprint and be mechanically robust. The preconcentrator must also have a short thermal time constant (10's-100's ms) while reaching an operating temperature of 100-200 deg C. By minimizing this period, the analyte plug desorbed from the preconcentrator arrives at the detector with increased amplitude,

\author{
Stuart Ross \\ Dstl. Porton Down, Salisbury, UK \\ David J. Nagel, Ioana Voiculescu \\ Department of Electrical Engineering \\ George Washington University, Washington, DC
}

improving the overall signal to noise ratio. The device's efficacy can be maximized by stacking the preconcentrator planes. They are therefore designed with perforations arranged so that a second layer that is rotated by $90^{\circ}$ will intercept analyte passing through the holes of previous preconcentrator planes.

Variations on the basic design depicted in Figure 1 were explored. The heater is a platinum dual serpentine either $25 \mu \mathrm{m}$ or $35 \mu \mathrm{m}$ wide. It defines an active region that is either $7 \mathrm{~mm} \times 7 \mathrm{~mm}$ or $6 \mathrm{~mm} \times 6 \mathrm{~mm}$ depending on the design variation. It is composed of a sputtered $\mathrm{Cr} / \mathrm{Pt}$ layer, $0.02 \mu \mathrm{m}$ and $0.16 \mu \mathrm{m}$ thick respectively. The heaters are supported by a $6 \mu \mathrm{m}$ thick layer of polyimide perforated with an array of rectangular openings $(375 \mu \mathrm{m} \times 125 \mu \mathrm{m})$. The open area fraction within the active region is either $\sim 42 \%$ (high perforation density) or $\sim 21 \%$ (low perforation density). Relatively large apertures around the outside of the active area serve to isolate it from the cool silicon frame while preventing development of excess pressure drop at flow rates up to $0.5 \mathrm{~L} /$ minute.

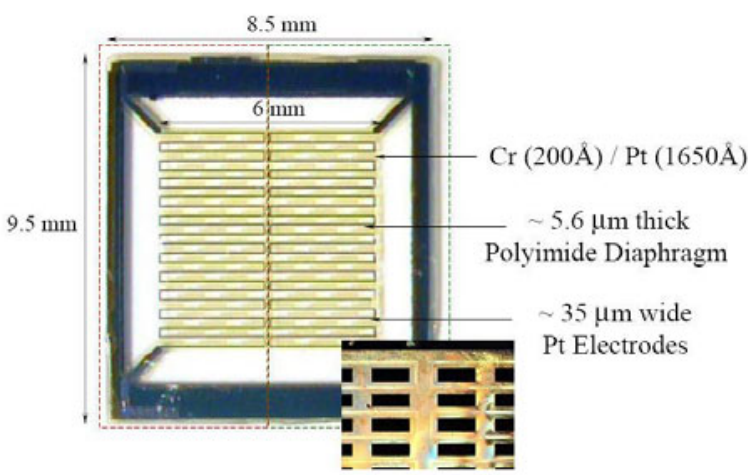

Figure 1 Micrograph of a $6 \mathrm{~mm} \times 6 \mathrm{~mm}$ prototype CASPAR preconcentrator

\section{SIMULATION}

The finite element analysis (FEA) software, CoventorWare ${ }^{\mathrm{TM}}$, was used to model the behavior of the polyimide hotplates. It allows simulation of Joule heating within an electrode and calculation, in three dimensions, of either the transient or steady state thermal distribution. Given that thin film properties vary significantly from their bulk values, the Temperature Coefficient of Resistance (TCR) for the sputtered platinum heater was measured for 22 separate heaters, averaged together and incorporated as a look-up table in the FEA.

A steady state analysis of a single $7 \mathrm{~mm} \times 7 \mathrm{~mm}$ design variant is presented here. It consists of a $5.6 \mu \mathrm{m}$ thick polyimide layer and 
$0.18 \mu \mathrm{m}$ thick platinum traces. The silicon frame and bond pads are not directly incorporated in the model. The geometry has a $35 \mu \mathrm{m}$ wide heater and high perforation density ( $42 \%$ open area). The average preconcentrator operating temperature as a function of voltage was investigated from $5 \mathrm{~V}$ to $35 \mathrm{~V}$ in $5 \mathrm{~V}$ increments and compared to experimentally determined values. The data are plotted in Fig. 2. The plot shows reasonable agreement with a significant systematic deviation occurring above $27 \mathrm{~V}\left(\sim 100^{\circ} \mathrm{C}\right)$.

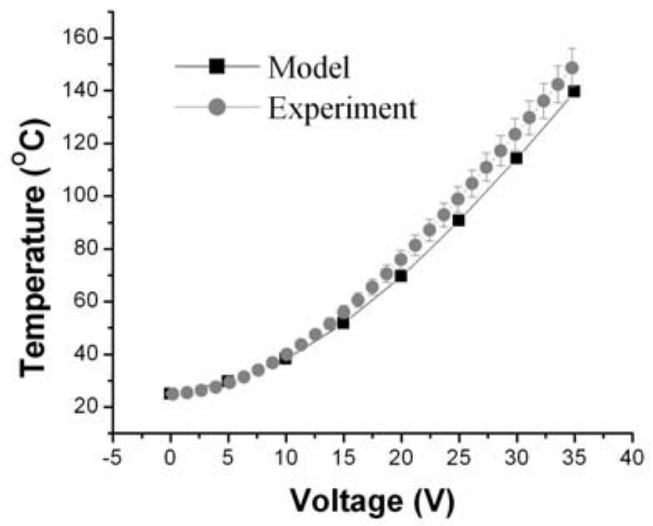

Figure 2 Comparison of simulated average temperature in the heater to experimental values as a function of voltage.

At an operating voltage of $30 \mathrm{~V}$ the corresponding average heater temperature was $\sim 120^{\circ} \mathrm{C}$, essentially the target value for the NRL absorbent polymer. The modeled temperature distribution over the hotplate surface at this voltage was investigated as well as the transient thermal response. The simulation data yields a time constant of $41 \mathrm{~ms}$ while the experimental yields $121 \mathrm{~ms}$.

\section{FABRICATION}

Devices are fabricated on $525 \mu \mathrm{m}$ thick (100) 4" silicon wafers on which a $0.45 \mu \mathrm{m}$ thick thermal oxide is grown. The oxide acts as both a masking layer on the back of the devices and as a stop layer at the front for Deep Reactive Ion Etching(DRIE). HDMS PI2611 polyimide is spin deposited and cured in a nitrogen atmosphere. The final polyimide thickness is $5.6 \pm 0.2 \mu \mathrm{m}$. Aluminum is sputtered on the cured polyimide and patterned to act as a masking layer for oxygen plasma etching. The etch step introduces the perforations in the polyimide. After removing the aluminum, a $\mathrm{Cr} / \mathrm{Pt}(0.02 \pm 0.03 \mu \mathrm{m}$ and $0.16 \pm 0.03 \mu \mathrm{m}$ thick, respectively) layer is sputter deposited and patterned using liftoff to produce the heaters. The polished side of the wafer is coated in $7 \mu \mathrm{m}$ thick positive resist in preparation for back side processing and subsequent dicing. Bulk etch windows for DRIE are opened on the back by spin coating with a $10 \mu \mathrm{m}$ thick negative resist. The resist is exposed after a back to front alignment to produce $8 \mathrm{~mm} \times 8 \mathrm{~mm}$ openings at the back of each die. The exposed oxide is removed in a buffered oxide etch. Before DRIE, the wafer is diced into individual die. The hotplates are plasma etched in groups of up to 16 in order to minimize etch rate variations caused by the large exposed silicon area on the back. DRIE is performed in a MESC Multiplex from Surface Technology Systems, Plc. for $\sim 4$ hours using 3 different platen biases in separate steps. Once the oxide stop layer is exposed the samples are removed from the DRIE and cleaned. Before testing, the sorbent polymer is selectively deposited in the active area using an inkjet printer.

\section{EXPERIMENT}

Prototypes were characterized by measuring resistance as a function of temperature in a probe station. The current for the resistance measurement was fixed to $10 \mu \mathrm{A}$ to avoid heating the hotplate. The chip was mounted on a thermal chuck and the temperature was varied from $25^{\circ} \mathrm{C}$ to $200^{\circ} \mathrm{C}$. During the

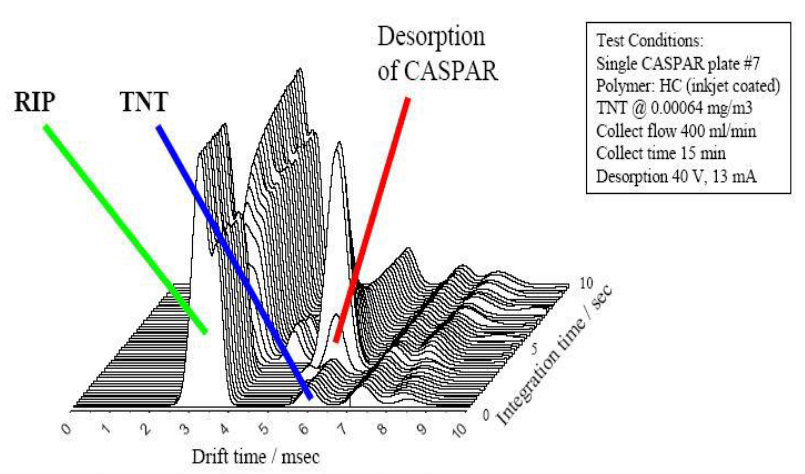

Figure 3 Initial preconcentrator testing using Vapor Tracer II IMS. The RIP is a Reactive Ion Peak used to transfer charge to the analyte before it is accelerated in the drift tube.

measurement, nitrogen gas was used to purge the chamber to avoid problems with water condensation.

The temperature versus resistance data were used to determine the temperature coefficient of resistance (TCR). These data were also used as a calibration so that temperature versus power, voltage and time could be found.

The performance of sorbant coated micro-hotplates was qualified by interfacing the device to the front end of an IMS system. 2,4,6Trinitrotouluene at a concentration just below the inherent detection limit of the IMS was introduced through a thermostatic column for periods ranging from 10 seconds to 30 minutes. Subsequent desorption from a CASPAR prototype produced at least an order of magnitude increase in analyte concentration, see Figure 3.

\section{CONCLUSIONS}

A single preconcentrator plane has demonstrated at least an order of magnitude improvement in the detection threshold of a portable IMS explosive detector. The prototype achieved a temperature of $120^{\circ} \mathrm{C}$ at $\sim 30 \mathrm{~V}$ in less than $120 \mathrm{msec}$ while consuming a total of $175 \mathrm{~mW}$ in a DC drive mode. Direct measurements of the two dimensional thermal distribution has yet to be performed. However, simulation indicates up to $50^{\circ} \mathrm{C}$ variation in temperature over the hotplate surface at the operating voltage of $30 \mathrm{~V}$ and a heater temperature of $120^{\circ} \mathrm{C}$. This problem is caused by the relatively low thermal conductivity of the polyimide layer. Future designs will incorporate a metal thermal distribution plate sputtered onto the back of the preconcentrators.

\section{REFERENCES}

1. Eric J. Houser, Duane L. Simonson, Jennifer Stepnowski, Stuart K. Ross, Stanley V. Stepnowski III and R. Andrew McGill. "Design of Hydrogen Bond Acidic Polycarbosilanes for Chemical Sensor Applications", ACS Polymer Preprints, 45 (1): March 2004.

2. J.I. Baumbach and G.A. Eiceman,'Ion Mobility Spectrometry: Arriving On Site and Moving Beyond a Low Profile", Applied Spectroscopy, 53, 338A (1999)

3. Manginell, R.P.; Frye-Mason, G.C.; Kottenstette, R.J.; Lewis, P.R.; Channy Wong, C., "Microfabricated planar preconcentrator", Technical Digest. Solid-State Sensor and Actuator Workshop, Hilton Head Isl., SC, Transducer Research Foundation, Cleveland (2000) pgs. $179-182$. 